\title{
SMS MARKETING: IT'S PLACE IN MOBILE COMMERCE AND OPPORTUNITY IN THE SOUTH AFRICAN MARKET
}

\author{
Frik Jansen van Ryssen, Cyclone Projects \& Consulting
}

This article investigates Short Message Service (SMS) Marketing's place in the world of mobile commerce (m-commerce). The article also investigates the opportunity that SMS Marketing presents in the South African market.

The article indicates a couple of clear guidelines and implications for marketers on how to approach the challenge presented by technological advances that allowed this new trend of mass- and personalised marketing messages via SMS.

Advances in the m-commerce field are predicted, and an indication of the proposed target market is provided. Of these devices, the cellphone is the most relevant to the article, because it is the main vehicle through with SMS's are sent and received.

It is concluded that SMS Marketing requires a great amount of investigation by every marketer and that continuous monitoring will be required in order for companies not to fall behind or be caught napping by competitors.

Keywords: m-commerce, SMS, marketing

\section{INTRODUCTION}

In a new global and knowledge economy, there is high competition among the organisations to attract customers. The sales cycle and time to make decisions are becoming more limited than ever. Moreover, the availability of large volume of information and rapid technology advancements increase customers' expectations at a faster rate.

Devices and systems based on mobile technologies are now commonplace in everyday life. These devices include cellular telephones (cellphones).

There has been a number of commentary recently discussing the implications of these technologies from a business perspective (Bergeron, 2001:lot154; Kalakota and Robinson, 2002:78; Keen and Mackintosh, 2001:207; Lamont, 2001:59; Newell and Lemon, 2001:126), indicating how some of these hi-tech devices can be used to streamline certain operational activities, such as inventory control, etc.

According to Haque (2004:257), mobile phones are now taking the place of conventional telephones in residential use, enabling users to live and work in more flexible and convenient ways.

When looking at marketing communication from a consumer perspective the issue of media effectiveness is challenging. The increased number of media has led to a tougher competition for consumers' attention and time as these have increasingly become scarce resources for consumers in the information age (Seybold, 2001:78).

In today's post-PC consumer electronics market, where consumers are more familiar with computers than ever before, few things can compare to the success of mobile hand-held devices. According to Shim and Shim (2002:199), the decreasing prices of mobile devices are fuelling this hyper growth of $m$-commerce. The decreasing prices are a result of market competitiveness and the establishment of open standards for wireless application development. 


\section{THE PURPOSE OF THE ARTICLE}

The biggest development since the entry of the cellphone into the market in 1994 was arguably the introduction of the short message service or SMS. This facility allows cellphone users to communicate with each other via text messages, quickly and effectively. And just months after its launch, thousands of users across the country were attracted.

While a number of authors (Davies, 2003:14; Westell, 2003:144; Jones, 2003:13; Makota, 2003:16) agree that SMS Marketing has great opportunities as a marketing communication and advertising tool, there is no clear indication except for a slight attempt by Varshney and Vetter (2002:187) to point out where SMS Marketing fits into Mobile Commerce (m-commerce). There is also a need to identify the opportunity presented by SMS Marketing for South African firms.

The purpose of this article is therefore to clearly point out exactly what is understood by m-commerce, where SMS marketing fits into m-commerce, the opportunities presented by SMS marketing, and how this relates to the South African market. The article will also give guidelines and recommendations to marketers.

\section{RESEARCH METHODOLOGY USED}

The research is based on a literature study, where the collected information is described, interpreted and evaluated on a qualitative basis to address the purpose of this article. No empirical study was undertaken. A great deal of literature was found on the particular topic, but the majority was very brief in its reference to SMS marketing, and concentrated more on m-commerce as a single entity. Recommendations, arguments and opinions of the researcher are therefore based on the literature study.

\section{THE LITERATURE STUDY}

This section concentrates on m-commerce, the place and uses of SMS marketing and the target market for SMS marketing.

\section{M-Commerce}

Wireless and mobile networks have experienced exponential growth in terms of capabilities of mobile devices, middleware development, standards and network implementation (Varshney and Vetter, 2000:134).

According to Balasubramanian, Peterson and Jarvenpaa (2002:349), m-commerce is the use of mobile (handheld) devices to communicate and conduct transactions through public and private networks. According to Raisinghani (2002:3), m-commerce relies on the usage of wireless devices such as cellular phones from which a commercial transaction is triggered and where it is sometimes completed.

According to Balasubramanian et al (2002:349), m-commerce is conceptualised as any phenomenon that exhibits all of the following characteristics:

- It involves communication, either one-way or interactive, between two or more humans, between a human/s and one or more inanimate objects (such as databases), or between two or more inanimate objects (e.g. between devices).

- At least one of the parties engaged in the communication must be mobile, in the sense that his, her, or its ability to communicate is not contingent on being at a fixed physical location at a particular point in time.

- The communication must be maintainable during a substantial physical movement of at least one of the parties from one location to another. 
- The communication signals between parties must be primarily carried by electromagnetic waves, without direct sensory perception of the signals.

- If humans are communicating, at least one seeks to benefit economically from the communication, either in the short or the long run. If the communication is entirely between inanimate objects, such communication must be ultimately aimed at creating economic benefits for a human or a firm.

There are many wireless services and applications under the umbrella of $\mathrm{m}$-commerce, but generally they are grouped into two categories, namely consumer-based and business-based (Shim and Shim 2002:199).

Consumer-based m-commerce applications refer to normal daily commerce activities that are most likely to be conducted by anybody who is a user of a wireless device. Examples include receiving stock prices, finding restaurants, getting driving directions, shopping online, etc. These are the activities that people conduct in their daily lives as part of their lifestyles. SMS marketing will fall into this category.

Business-based m-commerce refers to business applications that are applied in a corporate or business environment to facilitate business transactions and to improve productivity within a company (WAP Forum, 2001). Examples in this category include mobile inventory tracking systems, mobile offices, wireless data centres, etc.

In both these models, although the complexity of the services differs from one another, the common theme is the same, namely that m-commerce services are personalised. In the case of the consumer-based application, a user subscribes to a wireless service provider and provides user preferences for the type of news or data one would like to receive. A service provider then provides the information about that particular area of interest, and nothing else.

M-commerce activities would need to be short, concise and right to the point, because wireless networks are prone to dropping calls or interference and the bandwidth is usually smaller than wired networks (Cyberatlas.internet.com, 2001). Varshney and Vetter (2002:185) state that countries with a lack of regular telecom infrastructure are likely to adopt wireless and mobile communications to serve both urban and rural areas. This is very relevant to South Africa, where the vast majority of citizens own cellphones, compared to the very small amount that has access to email, landline telephones, etc.

Yorulmaz and Ragas (2002:41) present a roadmap for m-commerce (Figure 1) that makes distinctions between the scales of behavioural change required from customers and the value proposition that $\mathrm{m}$ commerce represents.

Magura (2003:9) initially hypothesised that there are three factors that significantly affect both simple and more complex m-commerce transactions. These are convenience, site design and security. Her study found that convenience was the element perceived to be important and paramount for both high- and lowinvolvement purchases. Site design turned out to be of little relevance, while security was important only to low-involvement purchases.

The widespread adoption of m-commerce has been brought forward by favourable pricing structures, increased competition, greater quality of services, and declining costs for network operators (Rao, 2002:online). A new breed of pan-African companies is creating the mobile miracle in Africa (Rose, 2002:13). A distinctive feature of Africa's mobile revolution is that the major players are limited to a few service providers. Perhaps Econet and MTN both are the real heavyweights, with both companies recently forking out a hefty $\$ 285$ million each to secure two of the biggest prizes in Africa has to offer the private sector - a GSM mobile operator licence for Nigeria. The wealth of this prize can be seen in perspective by the fact that within six months of operation, both firms are estimated to have signed up at least 200,000 subscribers. Each could even reach 10 million subscribers at the peak time (Kumar 
and Zahn, 2003:516). The other major players in South Africa are Vodacom, the first South African mobile operator, and Cell C, which joined the market in 2002.

Figure 1: The M-commerce Roadmap

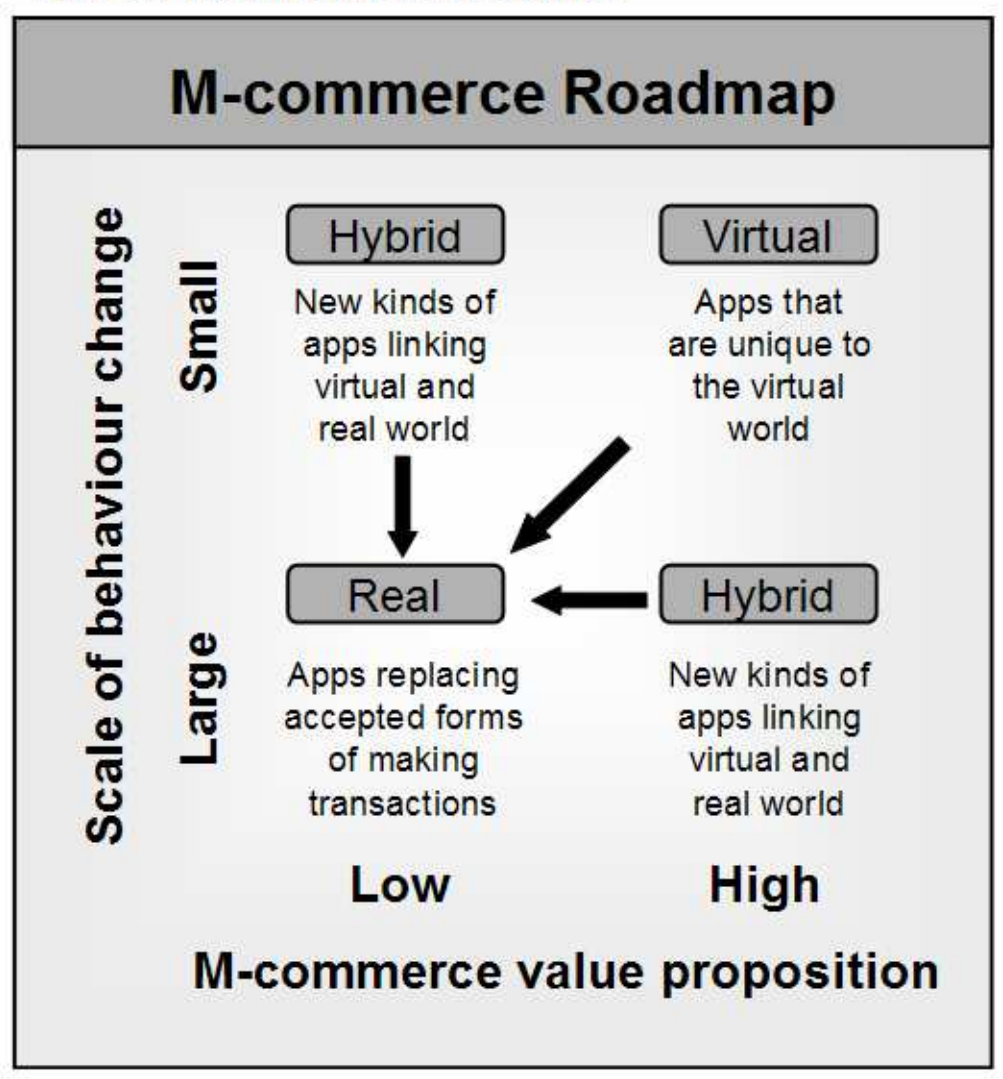

*Source: adapted from Yorulmaz and Ragas (2002:41)

It is already clear that many of the received views of marketing and many of its stalwart 'laws' and concepts will need to be re-thought in light of the marketing-related capabilities offered by mobile technology (Sheth and Sisodia 1999:83).

Meyers (2004:7) suggests that sociological trends and human behaviour must be understood before attempting to implement m-commerce, but contradicts himself by going on to say that neither of the two can ever be fully identified.

Raisinghani (2002:3) proposes that a pull as opposed to a push approach becomes a necessary requirement to promote $\mathrm{m}$-commerce.

There are a couple of frameworks proposed for m-commerce. Figure 2 is a framework for $\mathrm{m}$-commerce presented by Varshney and Vetter (2002:186). 
Figure 2: M-commerce Framework

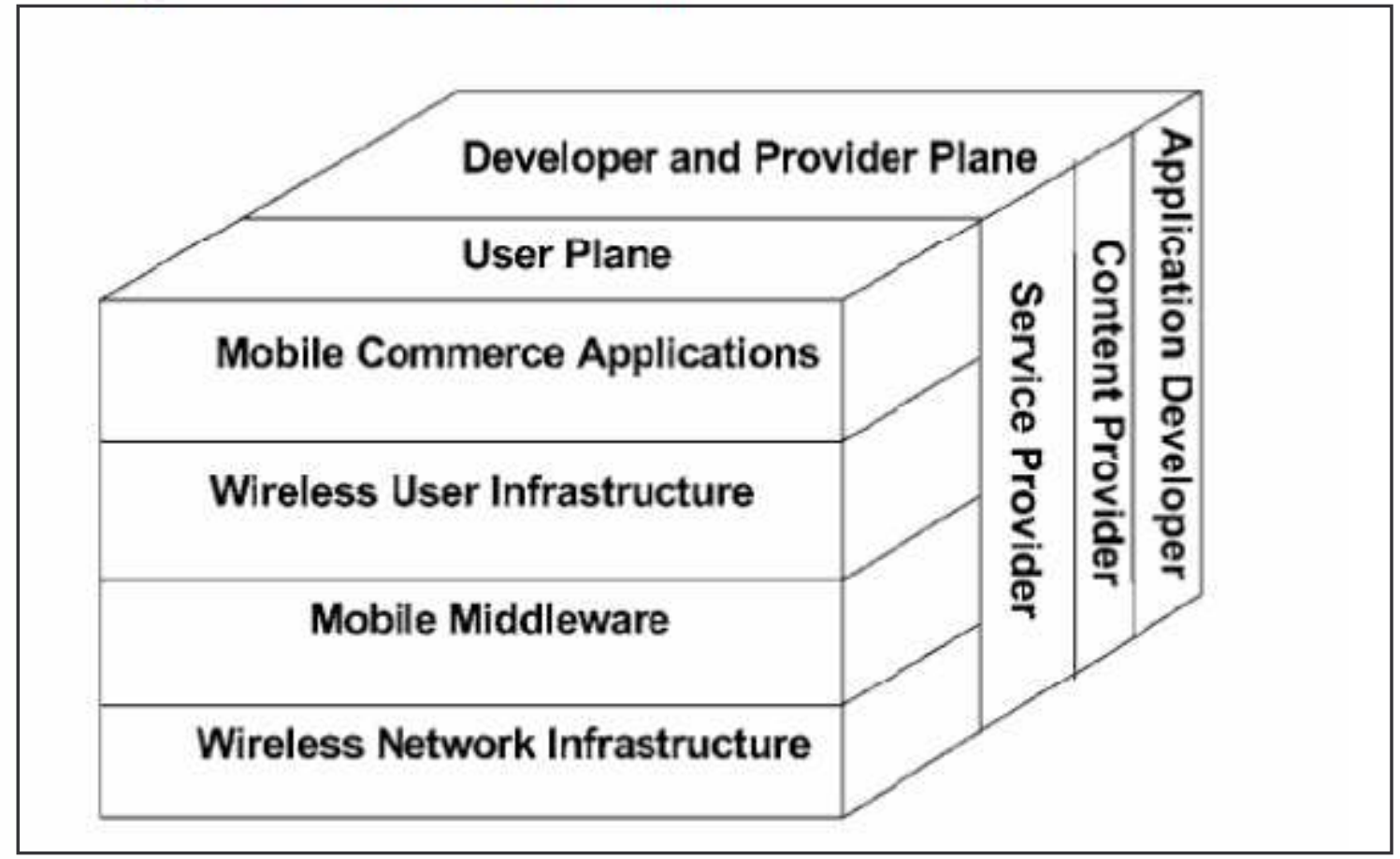

*Source: adapted from Varshney and Vetter (2002:186)

Varshney and Vetter (2002:186) also propose a life cycle for m-commerce. This life cycle can be seen in Figure 3. The framework and life cycle as depicted in Figure 3 gives some insight into the general functioning and positioning of m-commerce.

Shim and Shim (2002:203) state that a framework helps in straightening the ambiguities present in the design requirements. They continue by indicating that such a framework should achieve the following goals: it must be simplistic, scalable, secure and take user experience into account.

\section{SMS marketing's place in M Commerce}

SMS marketing is only one of the many facets of m-commerce. SMS marketing is the marketing communication activities undertaken by companies by sending either standard or personalised text messages directly to consumers. These text messages are received on consumers' cellphones, which can be read, saved, forwarded and even replied upon.

Using demographic information collected by wireless service providers and information on the current location of mobile users, targeted advertising can be done. The advertising messages can be personalised based on information provided by consulting the user at an earlier stage or by the history of users' purchasing habits. Advertisements sent to a user can also be location-sensitive and can inform a user about various on-going in surrounding areas, for example, shops, malls or restaurants can send information regarding special promotions, etc. Varshney and Vetter (2002:187) also provided a diagram of several mobile financial services (see Figure 4). 
According to Varshney and Vetter (2002:187), SMS marketing (sometimes also called mobile advertising) is a very important class of $\mathrm{m}$-commerce applications, as indicated in Table 1.

\begin{tabular}{|c|c|c|}
\hline \multicolumn{3}{|c|}{$\begin{array}{l}\text { Table } 1 \\
\text { Details and networking requirements of } \mathrm{m} \text {-commerce applications }\end{array}$} \\
\hline Class of applications & Details & Example \\
\hline Mobile financial applications (B2C, B2B) & $\begin{array}{l}\text { Applications where mobile devices becomes a } \\
\text { powerful financial medium }\end{array}$ & $\begin{array}{l}\text { Banking, brokerage, and payments for mobile } \\
\text { users. }\end{array}$ \\
\hline Mobile advertising (B2C) & $\begin{array}{l}\text { Applications turning the wireless infrastructure } \\
\text { and devices into a powerful marketing medium. }\end{array}$ & $\begin{array}{l}\text { User specific and location sensitive } \\
\text { advertisements. }\end{array}$ \\
\hline \multirow[t]{2}{*}{$\begin{array}{l}\text { Mobile inventory management (B2C, B2B) / } \\
\text { Product locating and shopping (B2C, B2B) }\end{array}$} & $\begin{array}{l}\text { Applications attempting to reduce the amount of } \\
\text { inventory needed by managing in-house and } \\
\text { inventory-on-move. }\end{array}$ & $\begin{array}{l}\text { Locating tracking of goods, boxes, troops, and } \\
\text { people }\end{array}$ \\
\hline & $\begin{array}{l}\text { Applications helping to find the location of } \\
\text { products and services that are needed. }\end{array}$ & $\begin{array}{l}\text { Finding the location of a new/used car of certain } \\
\text { model, colour and features. }\end{array}$ \\
\hline Proactive service management (B2C, B2B) & $\begin{array}{l}\text { Applications attempting to provide users } \\
\text { information on services they will need in very- } \\
\text { near-future. }\end{array}$ & $\begin{array}{l}\text { Transmission of information related to aging } \\
\text { (automobile) components to vendors. }\end{array}$ \\
\hline Wireless re-engineering (B2C, B2B) & $\begin{array}{l}\text { Applications that focus on improving the quality of } \\
\text { business services using mobile devices and } \\
\text { wireless infrastructure. }\end{array}$ & Instant claim-payments by insurance companies \\
\hline $\begin{array}{l}\text { Mobile auction or reverse auction (B2C, } \\
\text { B2B) }\end{array}$ & $\begin{array}{l}\text { Applications allowing users to buy or sell certain } \\
\text { items using multicast support of wireless } \\
\text { infrastructure }\end{array}$ & $\begin{array}{l}\text { Airlines competing to buy a landing time slot } \\
\text { during runway congestion (a proposed solution to } \\
\text { air-traffic congestion problem) }\end{array}$ \\
\hline $\begin{array}{l}\text { Mobile entertainment services and games } \\
\text { (B2C) }\end{array}$ & $\begin{array}{l}\text { Applications providing the entertainment services } \\
\text { to users on per event or subscription basis. }\end{array}$ & $\begin{array}{l}\text { Video-on-demand, audio-on-demand, and } \\
\text { interactive games. }\end{array}$ \\
\hline Mobile office (B2C) & $\begin{array}{l}\text { Applications providing the complete office } \\
\text { environment to mobile users any where any time }\end{array}$ & $\begin{array}{l}\text { Working from traffic jams, airport, and } \\
\text { conferences. }\end{array}$ \\
\hline Mobile distance education (B2C) & $\begin{array}{l}\text { Applications extending distance/virtual education } \\
\text { support for mobile users everywhere. }\end{array}$ & Taking a class using streaming audio and video. \\
\hline Wireless data centre (B2C, B2B) & $\begin{array}{l}\text { Applications supporting large amounts of stored } \\
\text { data to be made available to mobile users for } \\
\text { making "intelligent decisions. }\end{array}$ & $\begin{array}{l}\text { Detailed information on one or more products can } \\
\text { be downloaded by vendors. }\end{array}$ \\
\hline
\end{tabular}

The messages can be sent to all users located in a certain area (the geographic region can be identified by advertisers or even by users in advance); a user-specific message can be sent independently of the user's current location.

\section{The use of SMS marketing}

According to Mulrooney (2001:9), SMS is the ultimate one-to-one communication channel. SMS allows for access to customers' awareness in an unobtrusive one-to-one manner.

Mulrooney (2001:9) found that SMS marketing is especially valuable to the emerging market. In South Africa, many more people own cellphones that landline telephones and personal computers (PC's). SMS marketing has therefore a great opportunity to make an enormous impact on the South African market. A great deal of people in South Africa has access to electronic mail (email), but a limited number of people have twenty-four-hour access to these email accounts. It is for this reason that SMS marketing is the only real time advertising media in South Africa, seeing that any marketing message sent to a consumer will be read immediately, unless his/her cellphone is switched off, in which case the message will be received as soon as the cellphone is switched on again. 
Figure 3: M-commerce Life Cycle

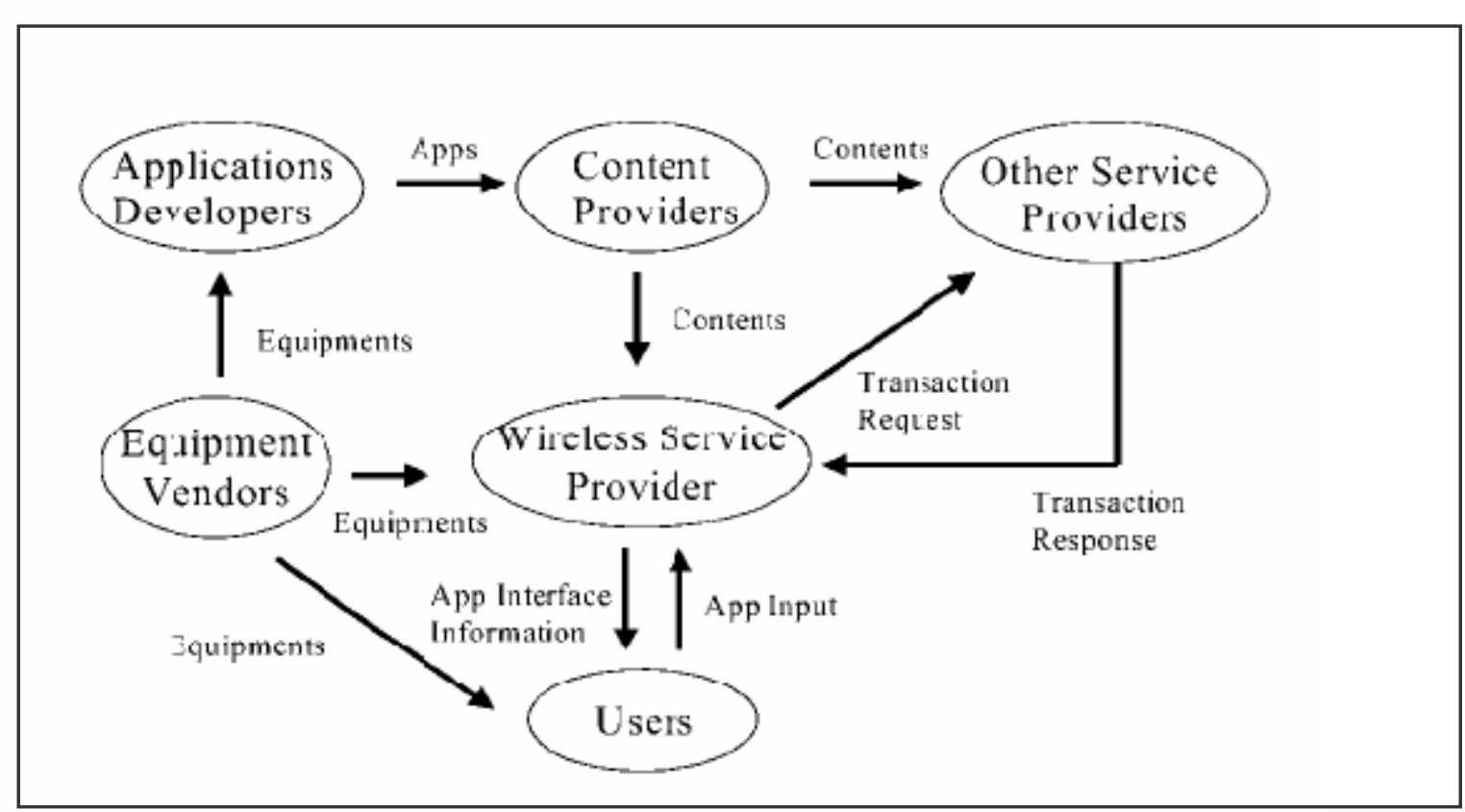

*Source: adapted from Varshney and Vetter (2002:186)

Figure 4: Several mobile financial services

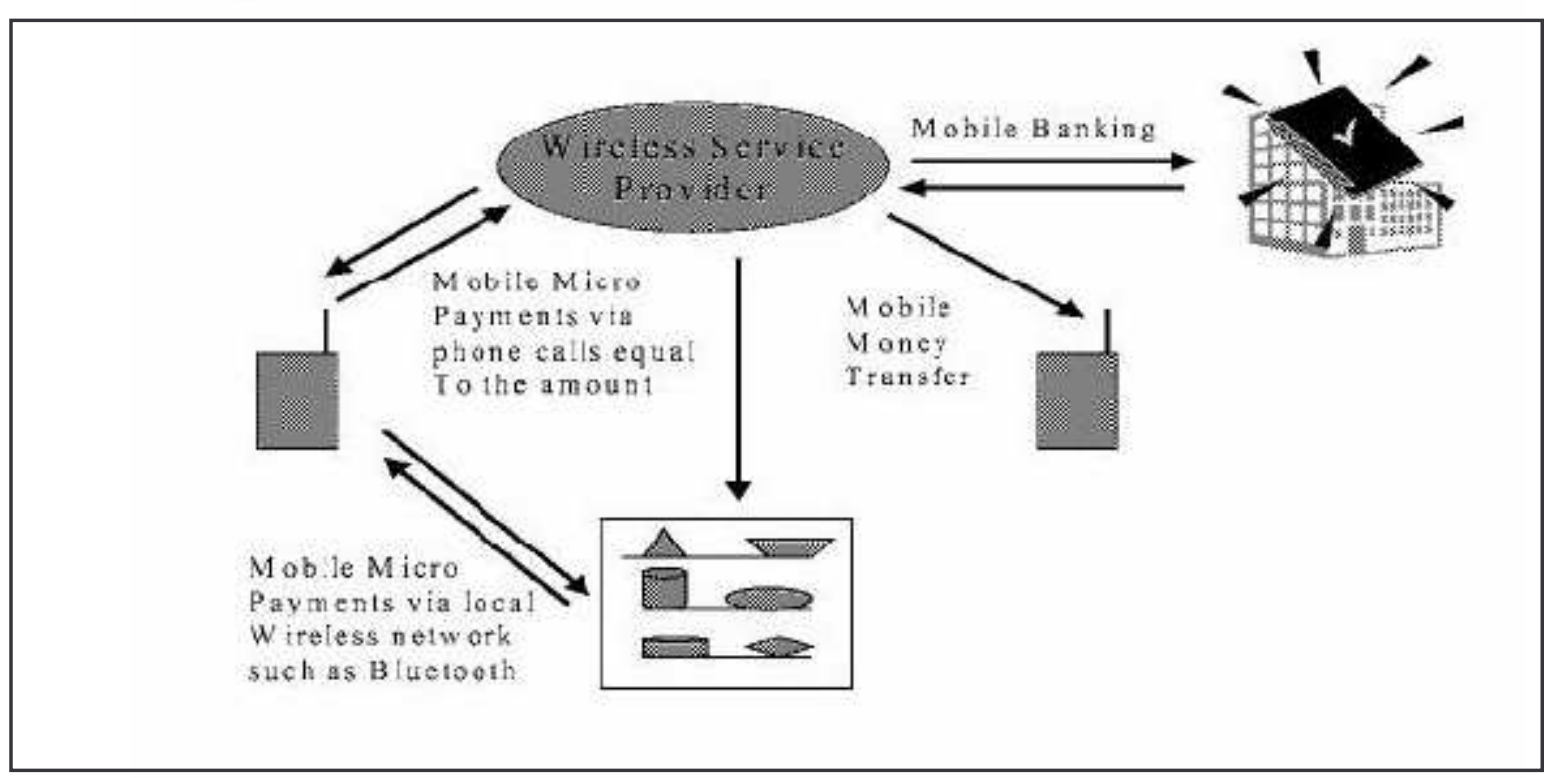

*Source: adapted from Varshney and Vetter (2002:187) 
Approximately $100 \%$ of these text messages received will be read first, without immediately deleting the message. This means that organisations get much better exposure of their messages. According to Lars Becker, CEO and co-founder of UK wireless marketing company Flytxt, people will receive your message, wherever they are (Flytxt, 2003:online).

According to Hanson (2003:24), carefully targeted and crafted messages receive above average response rates. Unlike the cumbersome reply mechanism of direct mail, it is easy to reply to mobile marketing campaigns because you reply through the same medium. According to Davies (2003:14), response rates of up to 11 per cent can be achieved with SMS marketing, compared to just 2 to 3 per cent for direct mail.

SMS, or mobile, marketing is generally used in conjunction with other channels for promotional campaigns, and as a way to communicate with existing customers. Its popularity is also enhanced by simplicity inherent in setting up campaigns, which is relatively straightforward compared to direct mail. Nothing needs to be printed, thus there is a rapid turnaround time. It can be low cost as an additional benefit, since there are no overheads.

Campaigns can be made even more effective for small companies if they move over to a self-service model after the initial model has been set up and the principles understood. Mulrooney (2001:9) does however suggest that it is extremely difficult to measure the effectiveness of this medium.

When a company is considering the use of SMS marketing, the following policies, regulations, ethical considerations and best-practice that should be kept in mind:

- Get permission: According to both Mulrooney (2001:9) and Hanson (2003:24), companies must be very careful to get permission, as a large scale outcry by customers because of invasion of privacy issues, can seriously damage any firm. Westell (2003:144) also mention that willingness of the audience impact on a campaign's success. Cowlett (2002:29) very clearly states that explicit consent prior to sending text messages must be obtained from target customers. Godin (1999:218) also suggests that permission marketing is critical. It was also argued by Marinova, Murphy and Massey (2002:67) that firms benefit from getting consumers' permission to be contacted.

- Provide opt-out options: This allows consumes to indicate if they no longer want to receive any communications from a particular merchant. Murphy (2003:23) also mentions that customers must be able to remove themselves from the company's database.

- Control spam: According to Mulrooney (2001:9), companies must only send messages to consumers who have indicated an interest in the topic/product/company concerned.

- Provide company detail: Mulrooney (2001:9) suggests that the companies should provide their detail at the end of marketing SMS's so that consumers can know exactly where the SMS originated.

- Use a database: According to Shim and Shim (2002:204) the database provides a data persistency mechanism for all the data necessary in a m-commerce framework. The personal information database stores user-specific data. According to Raisinghani (2002:3) a data warehouse is important, which allows a merchant to store and structure information so that the speed of event management access to information can be enhanced. According to Hanson (2003:24), media business such as magazines or radio stations can build up a database of text contacts via promotions or competitions.

- Respect privacy: This point is made by Hanson (2003:24). Customers are continually becoming more sensitive to privacy issues, and resistance can be experienced if customer's privacy is not respected.

- Provide clear value to the consumer: Hanson (2003:24) recommends that messages promoting or communicating anything, must clearly indicate what the consumer will gain from it. Customers 
want to be shown how they will benefit, and unless an offering can clearly show this, potential customers will simply delete your message.

- Never provide misleading messages: Customer expectations are one of the biggest drivers of ultimate customer satisfaction. Therefore it is critical to carefully manage messages communicated to customers and not over-promise and under-deliver, according to Jones (2003:13).

- Develop trust: Siau and Shen (2003:91) suggest that there are a couple of ways by which trust can be developed on a continuous manner - improve site quality, sharpen business competence, maintain company integrity, post privacy policy, strengthen security controls, foster a virtual community, encourage communication, increase accessibility and use external auditing to monitor operations. Trust will also be destroyed if customer's privacy needs aren't met (as discussed earlier).

- Personalise message: Companies can gain better consumer attention if messages are personalised to the individual recipient. These messages can also be targeted to certain segments, or even individuals. Marketing databases are loaded with sufficient information to effortlessly merge information to create targeted personalised messages.

- Educate customers: Yorulmaz and Ragas (2002:42). Customers need to understand what is expected of them, how compliance will ultimately benefit them and what information will be used for. Educated customers are more likely to participate and react to SMS marketing messages, than their uneducated counterparts.

\section{The target market for sms marketing}

Murphy (2003:23) suggests that SMS marketing is most successful when it is used for youth brands targeted to children and teenagers. Cowlett (2002: 29) agrees with this by stating that young people (sixteen to twenty four) are almost certainly carrying a mobile phone and considering SMS an intrinsic part of their lifestyle. He does however add that SMS marketing needs to be a two-way experience. Interactivity is thus very important. Mulrooney (2001:10) also states that both MTN and Vodacom (the two largest South African network providers) report substantial SMS usage among the youth market. According to Haque (2004:257), this market is growing at a phenomenal rate.

In contrast to this view, Hanson (2003:24) points out that regular use of text messaging is 60 per cent amongst 40-to-55-year olds. It is thus clear that any company considering SMS marketing, must do a proper analysis of their situation and all the environmental characteristics in order to determine whether SMS marketing will add value to the present marketing communication mix. Nokia predicts as many as 1.5 billion users worldwide by 2005. According to Anonymous (2003:9), over the next three years it is projected that this market will register six-fold growth. According to statistics from The Strategy Group (2002: online), more than 800 million cellphones and other mobile devices are in use worldwide.

\section{WHAT DOES THE FUTURE HOLD IN STORE?}

The future is looking extremely promising for SMS marketing and with technological developments, the possibilities will only increase. Mulrooney (2001:10) suggests that SMS marketing will become more important and more advanced as the cellphones available become more sophisticated.

According to Mulrooney (2001:10), one of the biggest advancements of late is advanced hardware that will allow up to 1000 characters per SMS. With such advances, marketing messages can be extensively longer in nature, communicating and providing more information and even including better aesthetics. According to Raisinghani (2002:4), more advanced viewing devices and data input devices must be developed to fully utilise all the opportunities presented by SMS marketing.

According to Yorulmaz and Ragas (2002:40), some of the technological developments that has taken place is $3 G$ (the much anticipated 'third generation' wireless infrastructure), as well as things like general 
packet radio service (GPRS), a standard for wireless communications more than ten times faster than current systems and especially suited for the small bursts of data sent in m-commerce. 3G networks are expected to include capabilities and features such as enhanced multimedia, high speed (upwards of 2 Mbps), and roaming capabilities (Raisinghani, 2002:3).

According to Hanson (2003:24), picture-messaging (Multi Media Service - MMS) will be more relevant as the new colour phones filter into the market. People's screens will grow bigger and pictures, sound and animation of pictures will open up many more opportunities for brands to communicate with the consumer in increasingly diverse and entertaining ways. With increased character possibilities, companies can even add additional value by cleverly using code to augment the SMS message.

According to Muller-Veerse (2003: online), the majority of the European market growth will be in the fields of financial, advertising (SMS marketing), and shopping services.

\section{IMPLICATIONS FOR MARKETERS}

SMS marketing can have profound implications for marketers.

The first implication is that marketers of all industries must first do an exhaustive environmental analysis to determine whether SMS marketing can be effective for them and their company. This analysis will include deciding whether their current target market will react to such marketing and/or whether one or more new segments can be targeted through this medium.

Once it is discovered that SMS marketing will indeed favourably impact the organisation, the SMS marketing strategy will have to be carefully planned. Included in this phase will be to consider all the recommendations made in this text by the researcher. These recommendations can then be implemented to establish the best possible campaign/s to gain customer awareness, encourage exploration and foster stronger relationships.

Regardless of whether SMS marketing is an appropriate strategy at the present point in time, marketers must continuously track and monitor advancements and developments, both technologically and concerning the target market/s and their needs. The SMS marketing strategies will need to be updated regularly to remain fresh. Updates might include different message communicated, lengthier messages, more use of multimedia or even targeting new market segments.

The last major implication for marketers is that they will have to establish the degree to which campaigns are or were successful. Even though measuring the effectiveness of such SMS marketing campaigns is difficult, great effort must be made by marketers to try and establish the success of campaigns.

\section{CONCLUSION}

SMS marketing has drastically affected the industry of marketing communications, adding another possibility for marketers to implement as part of their integrated marketing communications (IMC).

What must be kept in mind is that no matter what the impact of SMS marketing has had on one's industry, the traditional principles of advertising and communications still applies and must be carefully adhered to. It must also be noted that SMS marketing provides the opportunity for creative marketers to use their innovation to adapt to the new challenges offered by this technology.

It must also be considered that SMS marketing is only one of a great range of mobile commerce $(\mathrm{m}$ commerce) possibilities. Of these, SMS marketing must be the simplest, but the other possibilities offer additional opportunity to enhance the customers' experiences. 


\section{RECOMMENDATIONS FOR FUTURE RESEARCH}

This article was based on a literature study. For this reason it is recommended that future research on this specific topic be based on some empirical research.

It is further recommended that future empirical research focus on the awareness of SMS advertising, the effectiveness of SMS marketing on stimulating brand awareness, the spread of cellphone and SMS usage amongst the previously disadvantaged communities of South Africa and South African specific research on SMS Marketing target markets.

\section{REFERENCES}

Anonymous. 2003. Mobile commerce takes off. Focus Japan, 30(3):8-9

Balasubramanian S, Peterson RA \& Jarvenpaa SL. 2002. Exploring the Implications of M-Commerce for Markets and Marketing. Journal of the Academy of Marketing Science, 30(4):348-361

Bergeron B. 2001. The Wireless Web: How to Develop and Execute a Winning Wireless Strategy. New York: McGraw-Hill

Cowlett M. 2002. Text messaging to build youth loyalty. Marketing, October:29-30

Cyberatlas.internet.com, 2001. Mobile commerce frustrating many early users. [Online] Available from: http://cyberatlas.internet.com/markets/wireless/article/0, 10094 513431,00.html [Assessed 2004-05-16]

Davies HL. 2003. Industry must use best practice for SMS if it is to avoid junk label. Precision Marketing, April:14

Flytxt monthly newsletter [Online] Available from: http://www.flytxt.co.uk [Assessed: 2004-05-17]

Godin S. 1999. Permission marketing: Turning strangers into friends, and friends into customers. New York: Simon \& Schuster

Hanson S. 2003. The joys of text marketing. Precision Marketing, November:24

Haque A. 2004. Mobile Commerce: Customer Perception and Its Prospect on Business Operation in Malaysia. Journal of American Academy of Business, March:257-262

Jones D. 2003. Letter: SMS is giving itself bad name. Precision Marketing, March:13

Kalakota R \& Robinson M. 2002. M-business: The race to mobility. New York: McGraw-Hill

Keen PGW \& Mackintosh R. 2001. The Freedom Economy. Berkeley: Osborne/McGraw-Hill

Kumar S \& Zahn C. 2003. Mobile communications: evolution and impact on business operation. Technovation, 23:515-520

Lamont D. 2001. Conquering the Wireless World. Oxford: Capstone

Magura B. 2003. What hooks m-commerce customers? MIT Sloan Management Review, 44(3):9

Makota Y. 2003. M-commerce needs trust, convenience and usability. New Media Age, January:12 
Marinova H Murphy D \& Massey PK. 2002. Permission e-mail marketing as a means of targeted promotion. Cornell Hotel and Restaurant Administration Quarterly, February:61-69

Meyers J. 2004. Making a Market for Mobile Commerce. Wireless Review, March:7

Muller-Veerse F. 2003. Mobile commerce report [Online]. Durlacher Corporation, London. Available from: http://www.durlacher.com/downloads/mcomreport.pdf [Assessed 2004-05-18]

Mulrooney B. 2001. Directions: Getting personal. Direct Africa, February:8-10

Murphy D. 2003. Stopping careless texting to children. Marketing, April:23-24

Newell F \& Lemon KN. 2001. Wireless Rules: New Marketing Strategies for Customer Relationship Management Anytime, Anywhere. New York: McGraw-Hill

Raisinghani M. 2002. Mobile Commerce: Transforming the Vision into Reality. Information Resource Management Journal, 15(2):3-4

Rao M. 2002. EM-Wire: E-Commerce, M-Commerce poised for rapid take-off in Europe [Online]. Available from: http://www.electronicmarket.com [Assessed 2004-05-14]

Rose R. 2002. Mobile revolution: the new, home-grown graints. African Business, 4(March):10

Seybold P. 2001. The customer revolution: How to thrive when your customers are in control. London: Random House Business Books

Sheth JN \& Sisodia R. 1999. Revisiting Marketing's Lawlike Generalizations. Journal of the Academy of Marketing Science, 27(Winter):71-87

Shim G \& Shim SSY. 2002. A Service Management Framework for M-Commerce Applications. Mobile Networks and Applications, 7:199-212

Siau K \& Shen Z. 2003. Building customer trust in mobile commerce. Association for Computing Machinery. Communications of the ACM, 46(4):91-94

The Strategy Group, 2002 [Online]. Available from: http://strategiesgroup.com [Assessed 2004-05-13]

Varshney U \& Vetter R. 2000. Emerging wireless and mobile networks. Communications of the ACM, June:130-143

Varshney U \& Vetter R. 2002. Mobile Commerce: Framework, Application and Networking Support. Mobile Networks and Publications, 7:185-198

WAP Forum, 2001, WAP 1.1 specification [Online] Available from: http://www.wapforum.org [Assessed: 2004-05-15]

Westell S. 2003. Lawful data processing for email and SMS marketing. Business Information Review, 20(3):144-148

Yorulmaz T \& Ragas D. 2002. The M-Commerce Roadmap. E-commerce \& technology, July:40-42 